DIW BERLIN

Discussion Papers
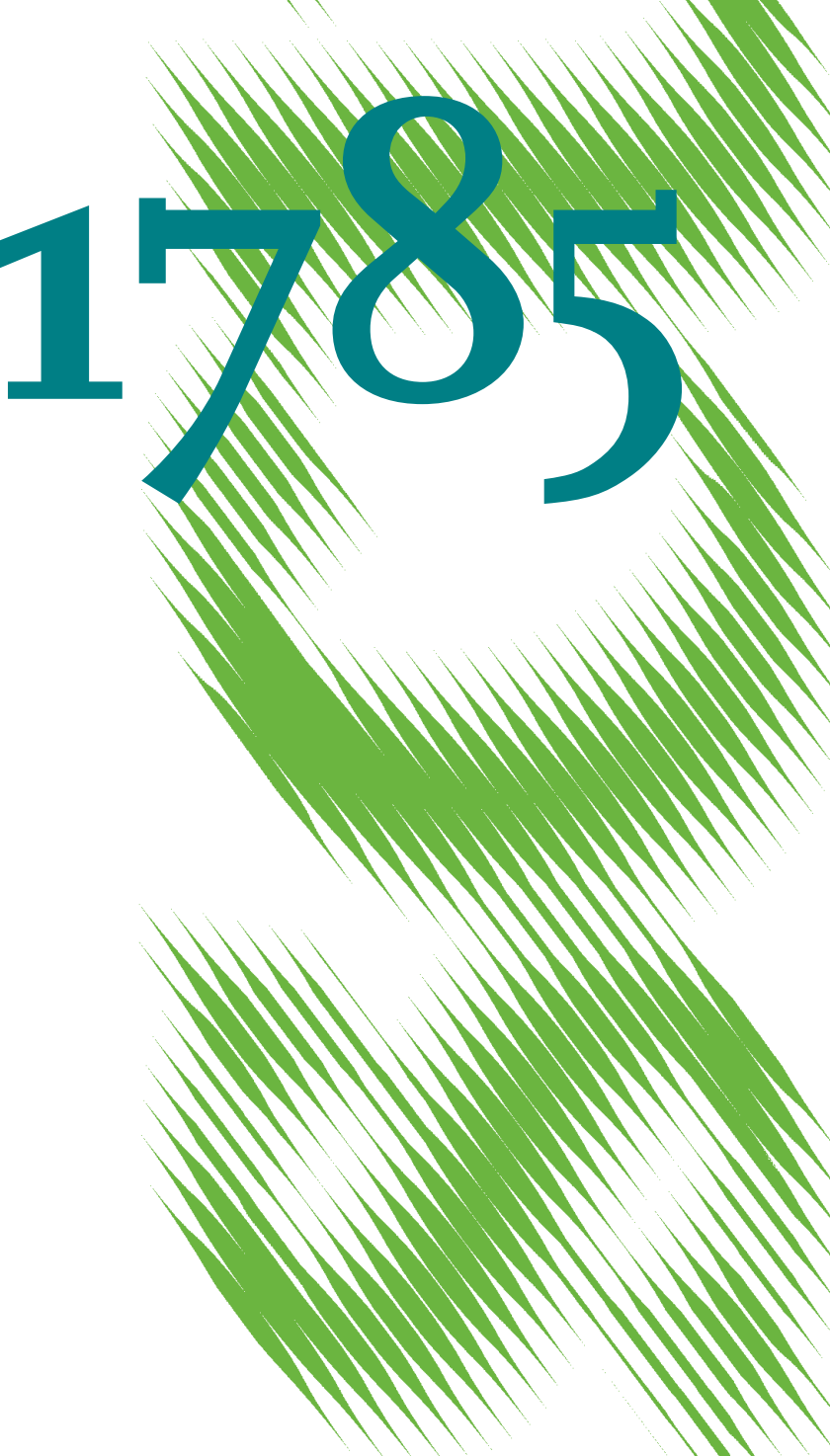

Mortality in Midlife for Subgroups in Germany 
Opinions expressed in this paper are those of the author(s) and do not necessarily reflect views of the institute.

IMPRESSUM

(C) DIW Berlin, 2019

DIW Berlin

German Institute for Economic Research

Mohrenstr. 58

10117 Berlin

Tel. +49 (30) $89789-0$

Fax +49 (30) $89789-200$

http://www.diw.de

ISSN electronic edition 1619-4535

Papers can be downloaded free of charge from the DIW Berlin website:

http://www.diw.de/discussionpapers

Discussion Papers of DIW Berlin are indexed in RePEc and SSRN:

http://ideas.repec.org/s/diw/diwwpp.html

http://www.ssrn.com/link/DIW-Berlin-German-Inst-Econ-Res.html 


\title{
Mortality in midlife for subgroups in Germany*
}

\author{
Peter Haan` Anna Hammerschmid $\ddagger$ Julia Schmieder
}

This version: January 28, 2019

\begin{abstract}
Case and Deaton (2015) document that, since 1998, midlife mortality rates are increasing for white non-Hispanics in the US. This trend is driven by deaths from drug overdoses, suicides, and alcohol-related diseases, termed as deaths of despair, and by the subgroup of low-educated individuals. In contrast, average mortality for middle-aged men and women continued to decrease in several other high-income countries including Germany. However, average mortality rates can disguise important differences between subgroups and the phenomenon of increasing mortality rates might also be present for subpopulations in these countries. Hence, we analyze how mortality in midlife is changing for several important demographic subgroups in Germany over the 1990 to 2015 period with a focus on deaths of despair. Our results show a very clear pattern: We find that mortality rates declined between 1990 and 2015, with no increases in deaths of despair for any of the subgroups. Thus, our findings starkly contrast with those for the US.
\end{abstract}

Keywords: Mortality, lifetime inequality, causes of death, deaths of despair, Germany. JEL classification: I10, I14, J11.

\footnotetext{
${ }^{*}$ Corresponding author: Julia Schmieder; Mohrenstraße 58, 10117 Berlin, Germany; phone: +49 3089789 334. For helpful discussions and comments, we thank Adam Lederer and Hannes Kröger and participants at the conference Demographics, Immigration, and the Labor Market. We thank Robert Lindner for his excellent research assistance. We are grateful for financial support from the DFG (Project HA5526/4-2) and from the German Federal Ministry of Education and Research within the JPI MYBL framework (Bundesministerium für Bildung und Forschung, Förderlinie: "IKT 2020 - Forschung und Innovation", Förderkennzeichen: 16SV7585, Projekt LONGLIVES). The support of the JPI MYBL is gratefully acknowledged.

${ }^{\dagger}$ DIW \& FU Berlin, NETSPAR; e-mail: phaan@diw.de

${ }^{\ddagger}$ DIW Berlin, BERA; e-mail: ahammerschmid@diw.de

$\S$ DIW Berlin, WU Vienna and IZA, e-mail: jschmieder@diw.de
} 



\section{Introduction}

Overall, life expectancy in most high-income countries is increasing over time. Mid-age mortality has become less of an issue for most of these countries and thus received only minor public attention in the past years. However, studies for the US show that, since 1998, mortality rates in midlife are increasing for white non-Hispanics (Case and Deaton, 2015, 2017). This trend is driven by deaths from drug overdoses, suicides, and alcohol-related diseases, termed as deaths of despair, and by the subgroup of low-educated individuals. This points at rising inequality in mortality by socioeconomic status within this ethnic group. Case and Deaton (2017) argue that the mechanism behind this development is likely to be the deterioration of life circumstances for low-educated white non-Hispanics over time, e.g. worsening of employment opportunities or increasing instability of marriages 11 At the same time Case and Deaton (2015, 2017) illustrate that in several other high-income countries, including Germany, average mortality in midlife continued to decrease after 1998. However, since the average mortality rates can disguise important differences between specific subgroups, it is unclear if the phenomenon of increasing mortality rates is also present for subpopulations in these countries.

In this paper, we focus on Germany by analyzing the trend in mortality rates for the middleaged by gender, marital status, and migrant background across both East and West Germany. Germany is particularly interesting because middle-aged individuals in East Germany lived through a period of severe changes due to the reunification of Germany in 1990. The transition for East Germany was remarkable: The socialist system that had prevailed for decades was changed to the West German setup of a social market economy. This led to higher average incomes, but also to substantial discontinuities in employment careers and to exclusion from the labor market (Mayer, 2006). About $75 \%$ of East German workers left their employer of 1989 and more than $40 \%$ experienced a spell of unemployment before 1996. Over the same time period, the unemployment rate in East Germany increased from around 1 to more than 20 percent (Krueger and Pischke, 1995; Goedicke, 2006a b). There were also drastic developments in fertility, marriage, and divorce rates in East Germany in the years around reunification (Nolte, 2000). The age-standardized all-cause mortality rate for East German men and women

\footnotetext{
${ }^{1}$ In contrast, $\operatorname{Ruhm}(2018)$ argues that the availability and cost of drugs is the main force behind increases in drug deaths.
} 
increased slightly immediately after reunification 2 In the 1990s, it decreased faster than for West German men and women, respectively, due to a substantial improvement in medical care in East Germany, a rapid change in diet because of greater availability of fruits and vegetable oils, and improving living standards (Nolte et al., 2000, Diehl, 2008; Kibele, 2012; Vogt and Vaupel, 2015). Since the early 2000s, women in East and West Germany have similar all-cause mortality rates and life expectancy at birth, while there is a stagnating gap between East and West German men (Robert Koch Institute, 2011; Vogt and Vaupel, 2015).

We extend the analyses of Case and Deaton $(2015,2017)$ for Germany in the time period from 1990 to 2015, analyzing how mortality in midlife changed for East and West German subpopulations with a focus on deaths of despair. For this study, we use the official cause-ofdeath statistics ("Todesursachenstatistik") in which all deaths and the reasons of deaths are recorded. We follow the analysis in Case and Deaton (2017) and calculate the mortality rates of the 50-54 age group, defined as the number of deaths in the given age group per 100,000 persons at risk. As a sensitivity analysis, we also look at mortality rates of the neighboring age groups 40-44, 45-49, and 55-59.

Our results show a very clear pattern. We find that mortality rates declined between 1990 and 2015, with no increases in deaths of despair for any of the subgroups. Thus, our findings stand in contrast with the experience in the US. Reasons for this difference might be related to the German welfare system, which provides a more generous safety net in dimensions essential to life.

\section{Data}

The analysis is based on data from the official cause-of-death statistics ("Todesursachenstatistik"), which is available from the Federal Health Reporting (Federal Health Reporting, 2018). It covers all deaths in Germany and is based on death certificates issued by a medical practitioner. The data is available at an aggregate level: we can look at the number of deaths from different causes in groups defined by year of death, age at death in five-year categories, residence at the state level, gender, and German nationality.

According to the rules of the WHO, the statistics are mono-causal, which means that only one underlying disease is recorded. The selection of a single cause is especially problematic

\footnotetext{
${ }^{2}$ This temporary increase in mortality during the transition affected mainly young and middle-aged men and was especially striking for deaths attributable to external causes and circulatory diseases (Nolte, 2000).
} 
for the elderly, since they often suffer from multiple diseases related to their death (Mathers et al. 2005, Robert Koch Institute, 2011). The statistics are based on the $9^{\text {th }}$ revision of the International Statistical Classification of Diseases (ICD-9) through 1997; thereafter based on ICD-10. This revision involved substantial changes. Therefore, comparisons of statistics on causes of death before and after 1998 must be made with caution. Moreover, the accuracy in the determination of the cause of death in Germany is not undisputed (Robert Koch Institute, 2011). However, using the proportion of deaths that have an undetermined cause as a measure for low reporting quality, we observe that the latter is much lower for the age group of 50-54 compared to the overall rate of $14 \%$ reported in Mathers et al. (2005) (see Appendix Figure A1). The proportion of unspecified deaths relative to all deaths in the age group 50-54 is well below 10\% for all subgroups. It increases slightly between 1990 and 2015, while being a bit higher for men than for women and for West than for East Germans.

Using population statistic: ${ }^{3}$ provided by the Federal Statistical Office, the absolute numbers of deaths are translated into death rates. The death rate is obtained as the number of persons in a selected group who died in a reference period in relation to 100,000 living persons in this group in the same reference period (Federal Health Reporting, 2018; Federal Statistical Office, 2018a).

We report all-cause death rates and deaths of despair rates for several subgroups aged 50-54 year: 4 in the 1990 to 2015 time period. The deaths of despair are defined according to Case and Deaton (2015), who provide the respective ICD-10 codes for their classification. These include suicide and intentional self-harm, chronic liver disease (alcoholic liver disease and cirrhosis), and poisoning (accidental and intent undetermined drug overdose and alcohol poisoning) 5 There were different coding practices for death causes prior to reunification and East Germany adopted the West German coding practices in the last quarter of 1990 Nolte

\footnotetext{
${ }^{3}$ The population statistics are based on intercensal updates, which are produced using the latest population census. Data on the population are rolled forward using statistical results on natural population change and on migrations across municipal borders using administrative data. Case and Deaton (2017) use data for Germany that rely on population statistics provided by the UN. There are some differences between the data sets, as \begin{tabular}{|l|l|l|l|l|l|}
\hline illustrated in Appendix Figure & A2 & that explain the differences between this study and Case and Deaton (2017)
\end{tabular} for the German deaths rates.

${ }^{4}$ Case and Deaton (2015) study mortality rates for a longer age window, i.e. for ages 45-54. The longer the age window, the more likely the analysis is to suffer from an aggregation bias due to the changing composition of the age group (Gelman and Auerbach, 2016). Thus, we choose the shorter window of ages 50-54. We additionally analyze the mortality in the neighboring age groups 40-44, 45-49, and 55-59.

${ }^{5}$ The Statistical Office of the European Community arranged selected important groups of deaths in the European Short List to ensure the continuity of the mortality data despite the changes in the ICD codes. For suicides and alcohol-related diseases, the classification coincides with the one by Case and Deaton (2015). For poisoning, we draw on the ICD-10 codes provided by Case and Deaton (2015) and identify the ICD-9 codes by comparing the descriptions of the corresponding codes.
} 
et al., 2000, Kibele, 2012). Importantly, deaths from suicide and liver cirrhosis that are crucial for our analysis were underreported in the German Democratic Republic. Hence, deaths of despair rates are expected to be understated for East Germany in 1990.

\section{Results}

\subsection{Trends in death of despair by region}

This section presents the results of our empirical analysis. We first show group-specific trends in all-cause mortality before turning to a deeper investigation of deaths of despair. Specifically, our analysis focuses on the differences between East and West German mortality trends.

Figure 1 shows the trends in all-cause mortality at ages $50-54$ by gender and region (East vs. West Germany), where East refers to territory of the former German Democratic Republic and West to the territory of the Federal Republic of Germany before October 1990 including Berlin. In line with higher female life expectancy, the overall mortality rates of women are lower than for men. For men, we find a considerable mortality gap between East and West Germany in the early 1990s. Up to the late 1990s, male mortality had fallen more rapidly in East Germany, closing part of the East-West mortality gap. However, the remaining gap has persisted, staying rather constant since the early 2000s. For women, the East German excess mortality has always been less pronounced. This East-West gradient entirely disappeared during the early 1990s. These trends based on gender and on East and West Germany resemble those reported in Robert Koch Institute (2011) for the age-standardized all-cause mortality for all age groups.

As shown in Figure 2, the pattern looks similar if we focus on the mortality rates from deaths of despair only, which again decrease for all groups. As mentioned earlier, the jump in the rates of deaths of despair from 1990 to 1991 for East German men and women is most likely driven by the change in the coding practice in East Germany following reunification. Keeping this in mind, the deaths of despair do not appear to evolve disproportionately to the general mortality for our groups of interest. However, persistent level differences show that deaths of despair are generally more pronounced in East than West Germany. We find that the continuing gap in deaths of despair between East and West German men can only partly explain why all-cause mortality has not been converging over the past decade (see Figure 1). In Appendix Figure A3 we show mortality from the most prevalent causes of deaths. The non-convergence in male 
all-cause mortality appears to be mainly explained by the non-decreasing East-West gap in deaths from neoplasms and from diseases of the circulatory system since the early 2000s.

In a sensitivity analysis, we look at the age groups 40-44, 45-49 or 55-59 in Appendix Figures A6, A7, and A8, respectively, and our observations do not change. Also, we extend our definition of deaths of despair to include smoking-related deaths. Figure A5 shows that the main conclusions of our analysis do not depend on the exclusion of smoking deaths. Death of despair rates of men and women in both parts of Germany remain still to be non-increasing:

In Figure 3, we go beyond the geographical differentiation between East and West Germany and show the number of deaths of despair by NUTS I region. Having this finer disaggregation, we have a small number of cases of deaths for some regions and hence more volatile trajectories 7 Still, we can conclude from Figure 3 that there is no evidence for an increase in deaths of despair in any of the NUTS I regions, neither for men nor for women. The convergence in deaths of despair for women between East and West Germany is also found between the NUTS I regions. For men, there is a convergence until the early 2000s. Beyond that, the gap in deaths of despair between NUTS I regions in East and to West Germany remains rather constant. The withincountry convergence for females over the time period from 1990 to 2015 and for males from 1990 until the early 2000s is consistent with unconditional beta-convergence, as defined by Gächter and Theurl (2011), which implies an inverse correlation between the starting values and the rates of change of mortality rates 8

In the following, we examine the deaths of despair more closely. The analysis in Figure 4 is concerned with the different causes of death that are labeled as deaths of despair and analyzes whether some of these sub-causes evolve differently over time for the different groups.

\footnotetext{
${ }^{6}$ Figure A4 shows only smoking related deaths by gender and region in the population of interest. We find a recent stronger increase in smoking related deaths for East compared to West German women, in line with Vogt et al. (2017). For men, we find a rather stable mortality in the East, whereas West German male mortality from smoking related diseases is downward sloped. The stronger upward trend for women as well as the non-decreasing trend for men could technically be indicative of "soft" deaths of despair. However, we think that this is unlikely for two reasons. First, if the trends in smoking in the East were indeed caused mainly by despair, then we would expect to see similar patterns in alcohol related deaths, which we do however not observe (see Figure 4). Second, it is unclear whether smoking is mainly considered as "drug of despair". A discussion in Vogt et al. (2017, second half of p. 1063) shows that evidence on the relationship between unemployment and smoking behavior is rather mixed.

${ }^{7}$ For example, the number of deaths of despair between age 50 and 54 in Bremen was on average about 8 (16) for females (males) in each year in the time period of the study.

${ }^{8}$ Additionally, we divide the NUTS I regions in two groups depending on their relative increase in real percapita household income and in their unemployment rate from 1990 to 2015 . We find that regions with a higher income growth (a faster decrease in unemployment) have higher initial levels in deaths of despair. These patterns then converge for women. For men, there is first a convergence and then a stagnating gap in deaths of despair rates. It is important to notice that the group with relatively faster improvements in income (unemployment) includes all NUTS I regions in East plus three in West Germany. Results are available upon request.
} 
For all groups, the largest share of deaths of despair are alcohol-related diseases, the second largest category consists of suicides. Poisoning is least often reported. We find that men have considerably higher rates of death in the former two categories compared to women. Within deaths of despair, the level differences between East and West Germany are most pronounced with respect to alcohol-related deaths. This observation lines up well with Nolte et al. (2000, 2003), who find that mortality from alcohol-related diseases was a major cause for the mortality gap between East and West Germans under the age of 65 in the 1990s. This difference is again larger for men compared to women. Until the mid 1990s, there was a decrease in the East-West gap for all of these three causes of death. The converging pattern for alcohol-related deaths in the 1990s is also reported in Nolte et al. (2003). To sum up, we do not find particularly different patterns for specific causes of death within the deaths of despair.

\subsection{Sub-group analysis}

In the remaining part of our analysis, we zoom further into subgroups of East and West German men and women. In particular, we study whether (non-German) nationality or marital status might identify groups for which mortality rates are on the rise, in a similar manner as for white non-Hispanics in the US (Case and Deaton, 2017, 2015).

In the first part of this exercise, we stratify the groups by nationality (German citizens versus non-German citizens) 99 For the cohorts in our analysis, there were around 233,000 to 275,000 men and 209,000 to 246,000 women with a foreign nationality in West Germany, mainly from Turkey, Italy, Greece, Poland, and Former Yugoslavia. In East Germany, there were about 9,000 to 13,000 non-German men and 6,000 to 9,000 women mainly from Poland, Russia, Hungary, and Vietnam. The size and the composition of the groups of non-Germans with respect to nationalities and gender was relatively constant over cohorts (Federal Statistical Office, 2018b).

As depicted in Figure 5, non-native individuals have lower mortality from deaths of despair compared to Germans. A potential explanation is that relatively healthy individuals select into migration, while potentially negatively selected migrants return to their home countries. Moreover, in the case of the so-called "Gastarbeiter" (guest workers) in Germany, health screenings were implemented: medical examinations only allowed relatively healthy individuals to enter Germany. With a potentially large group of Muslims among the non-Germans in our sample, there might also be some cultural "buffering" with respect to suicide and alcohol consumption

\footnotetext{
${ }^{9}$ Unfortunately, we cannot zoom further into non-German citizens because of data restrictions.
} 
Kohls, 2008). Overall mortality trends do not look substantially different ${ }^{10}$

Figure 6 shows the mortality trends in deaths of despair over time if we stratify our population groups by marital status. Looking into marital subgroups does not alter our conclusion. Overall, we do not observe increasing mortality from causes of despair for any of the subgroups. However, the interpretation of these trends is more difficult in this case, since the composition of the analyzed subgroups changed substantially over time: the share of single women and men increased by a factor of 2.5 from cohorts observed in 1998 to those in 2015, while the share of married decreased substantially. Hence, there might be a very different selection of individuals into a specific family status over time. The level differences by marital status, i.e. the fact that married have on average lower mortality rates from deaths of despair than single or widowed/divorced individuals, parallels the findings with respect to all-cause mortality in the meta-analysis by Manzoli et al. (2007). Of course, the mortality advantage of married individuals can be driven by both selection and causation. Still, Bulanda et al. (2016) argue that there is strong evidence of a causal relationship between marital status and mortality.

Overall, our empirical analysis cannot identify a specific group with rising mortality from causes of despair within the demographic dimensions under study. Even middle-aged East German men, who experienced severe changes in their lives for decades, do not face increasing deaths of despair rates in a similar manner as white non-Hispanics in the US Case and Deaton, 2015, 2017). We additionally analyze important demographic subgroups and do not find any group by citizenship or marital status that experienced a reversal in their deaths of despair mortality trends.

\section{Discussion}

In this study, we analyze mortality patterns and trends across important demographic groups in Germany. We focus on population groups defined by key demographic dimensions, such as gender, marital and migrant status across East and West Germany. These can be related to societal and economic status. In particular, East Germans experienced decades of extreme economic and societal change due to the division of the country and the transition of the political system in the early 1990s. Our results show a very clear pattern. In contrast to the US Case

${ }^{10}$ Note, however, that the trend gets very noisy for East German non-natives because of low cell sizes. The absolute number of deaths of despair in the group of East German non-native women is so small (and sometimes even zero) that we decided not to include them in the graph. 
and Deaton, 2017, 2015), we find that mortality rates declined between 1990 and 2015, with no increases in deaths of despair for any of the subgroups. There are various explanations why the pattern in Germany and the US is different. One important reason might be related to the German welfare system. Unemployment insurance, social benefits, and mandatory health insurance provide a broader and more generous safety net for individuals who experience economic or social shocks, in particular during middle age. Moreover, following on the ongoing opioid addiction crisis in the US (see for example Currie et al. (2018)), which is particularly pronounced for middle-aged men, the German health care system and pharmaceutical regulations might have been more successful at preventing large-scale drug addiction and its related mortality (Fischer et al., 2014, Häuser et al., 2017). 


\section{$5 \quad$ Figures}

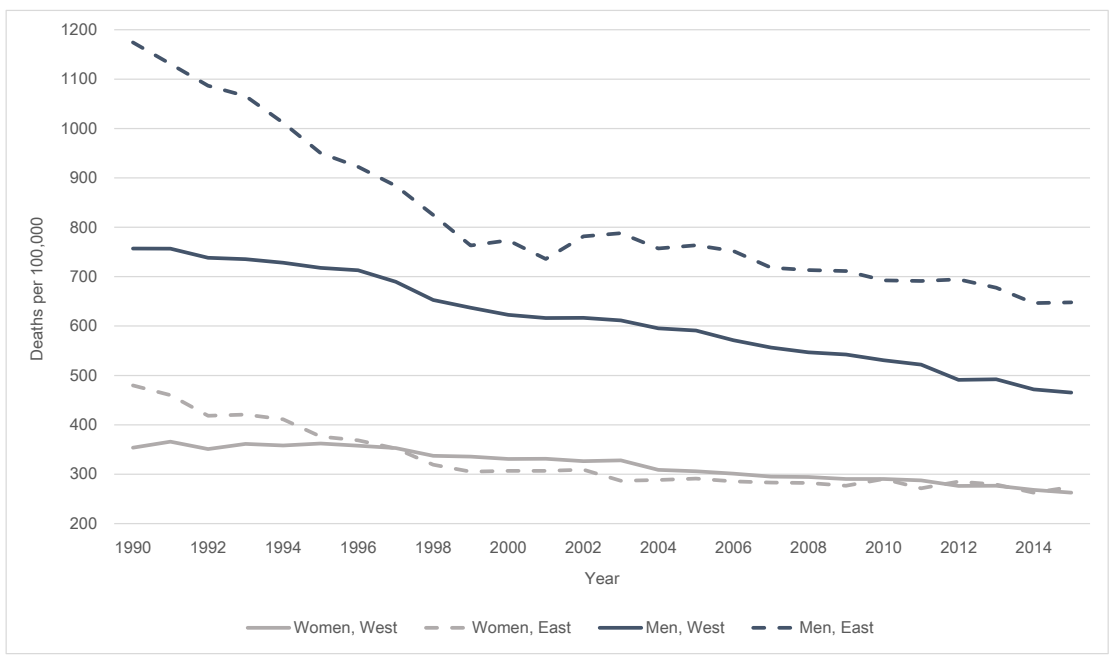

Fig. 1: All-cause mortality for age 50-54, Germany, 1990-2015, Source: Federal Health Reporting

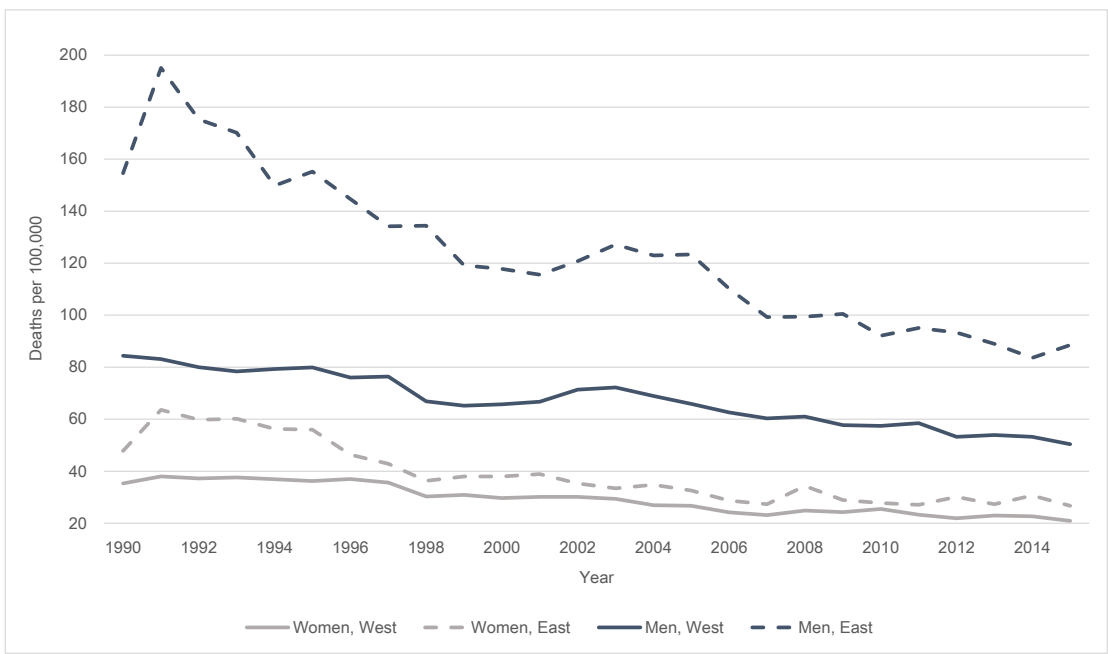

Fig. 2: Deaths of despair for age 50-54, Germany, 1990-2015, Source: Federal Health Reporting 


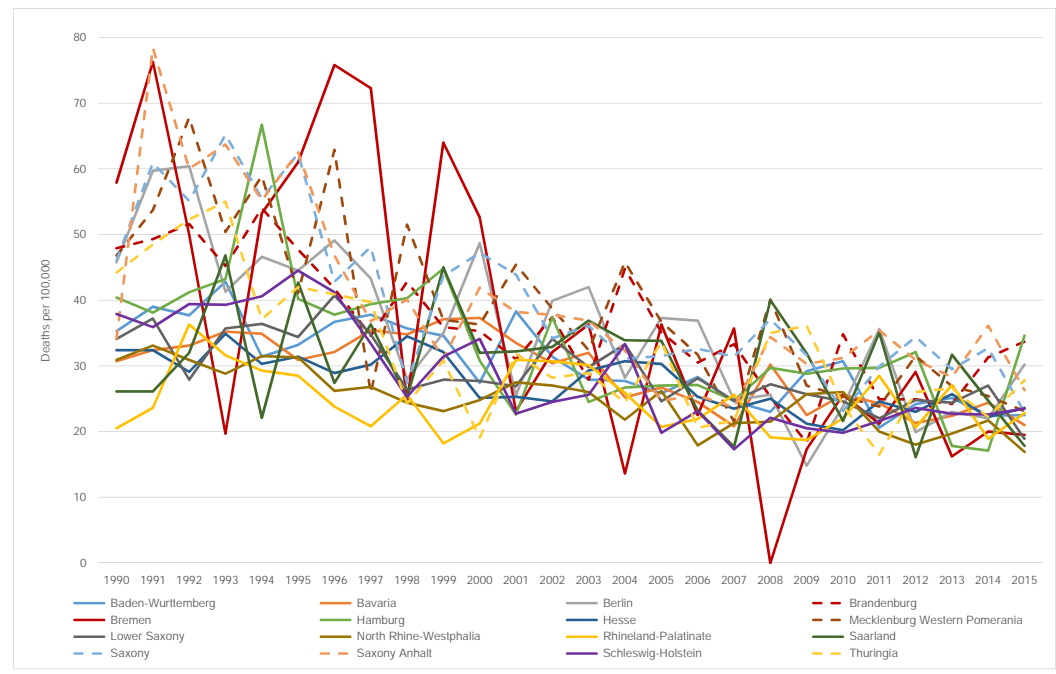

(a) Women

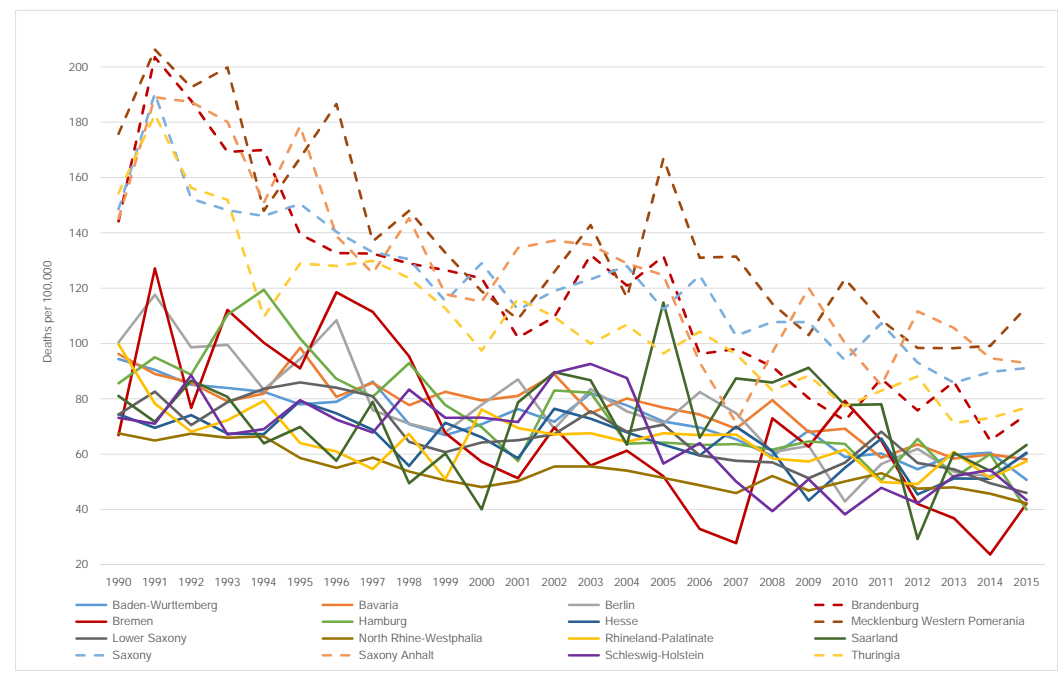

(b) Men

Fig. 3: Deaths of despair for age 50-54 by NUTS-I region, Germany, 1990-2015. Solid (dashed) lines show NUTS-I regions in West (East) Germany. Source: Federal Health Reporting 


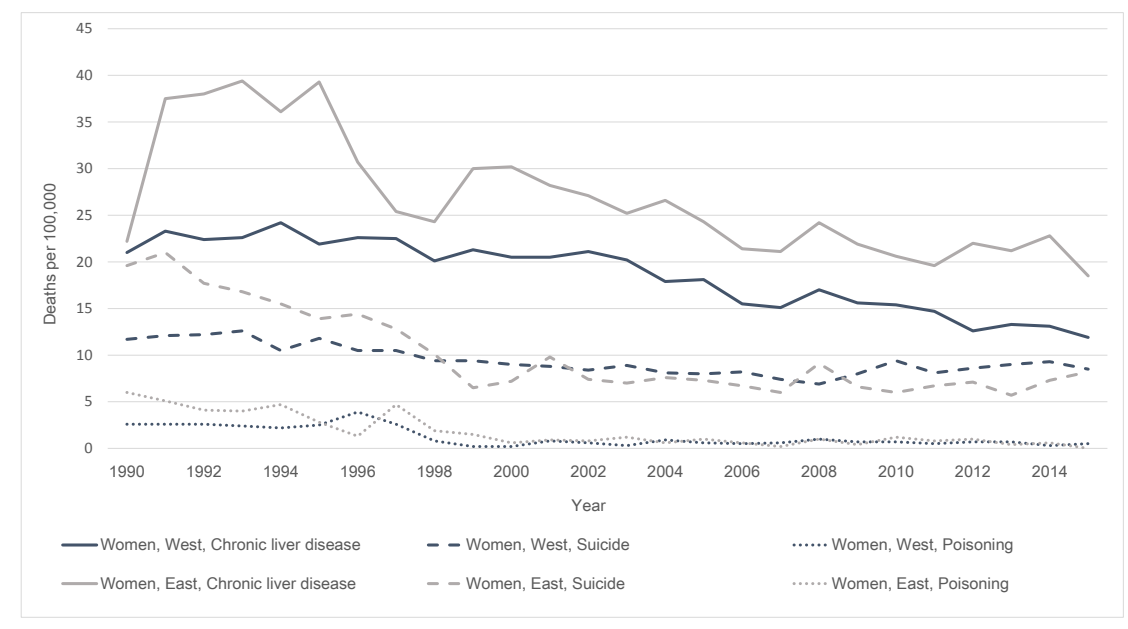

(a) Women

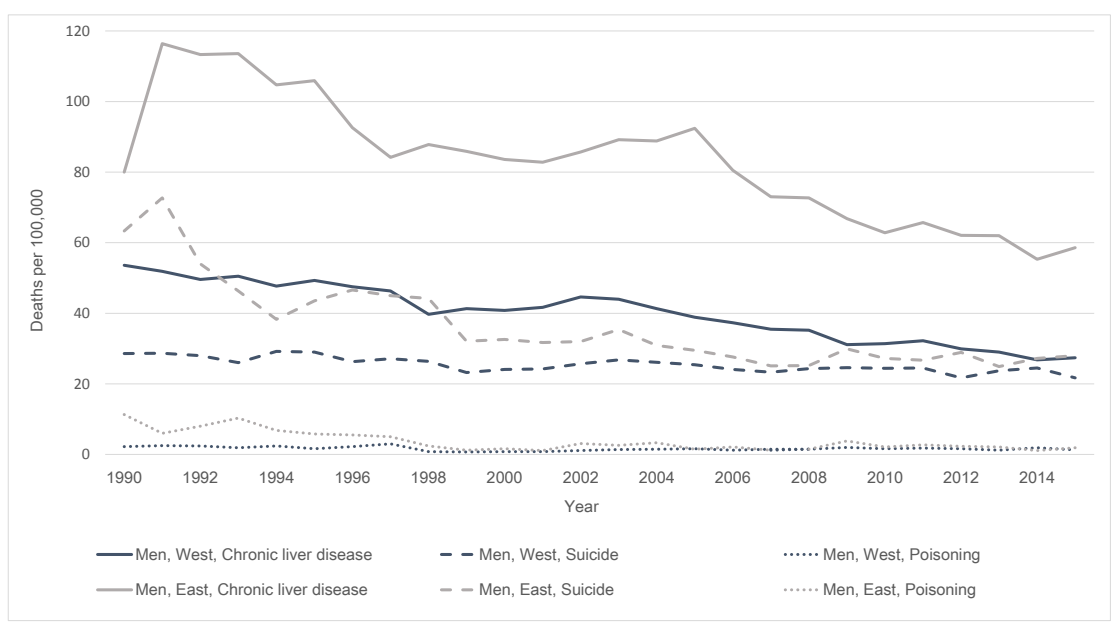

(b) Men

Fig. 4: Deaths of despair by causes for age 50-54, Germany, 1990-2015. Source: Federal Health Reporting 


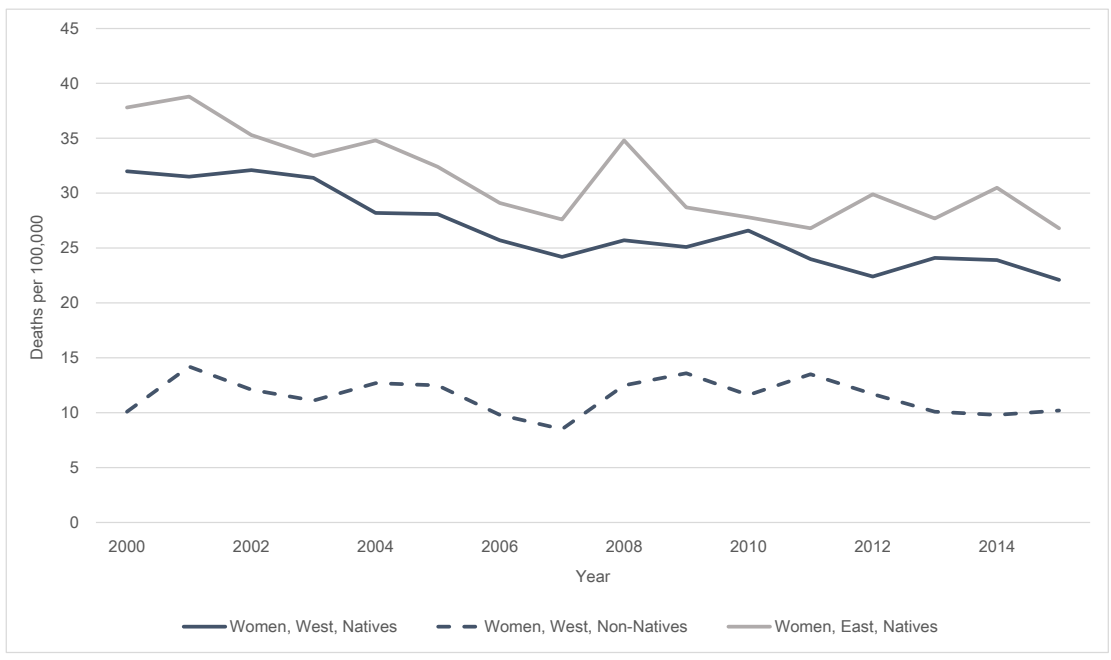

(a) Women

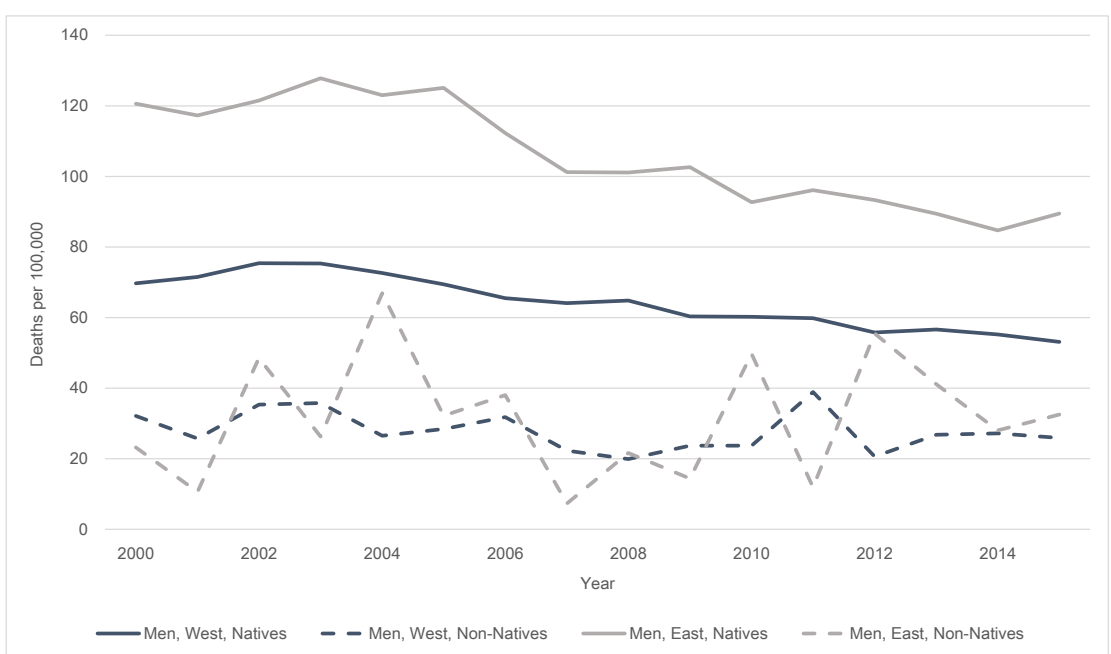

(b) Men

Fig. 5: Deaths of despair by nationality for age 50-54, Germany, 2000-2015. The absolute number of deaths of despair in the group of East German non-native women is so small (and sometimes even zero) that we decided not to include them in the graph. Mortality figures by nationality are only available after 2000. Source: Federal Health Reporting. 


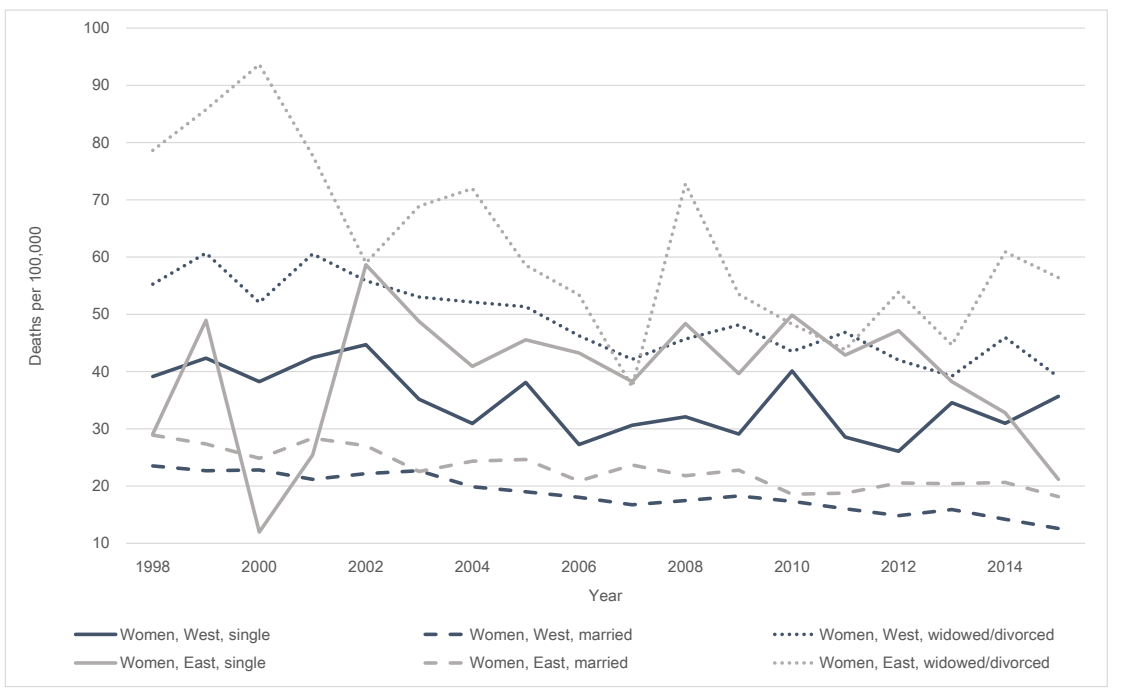

(a) Women

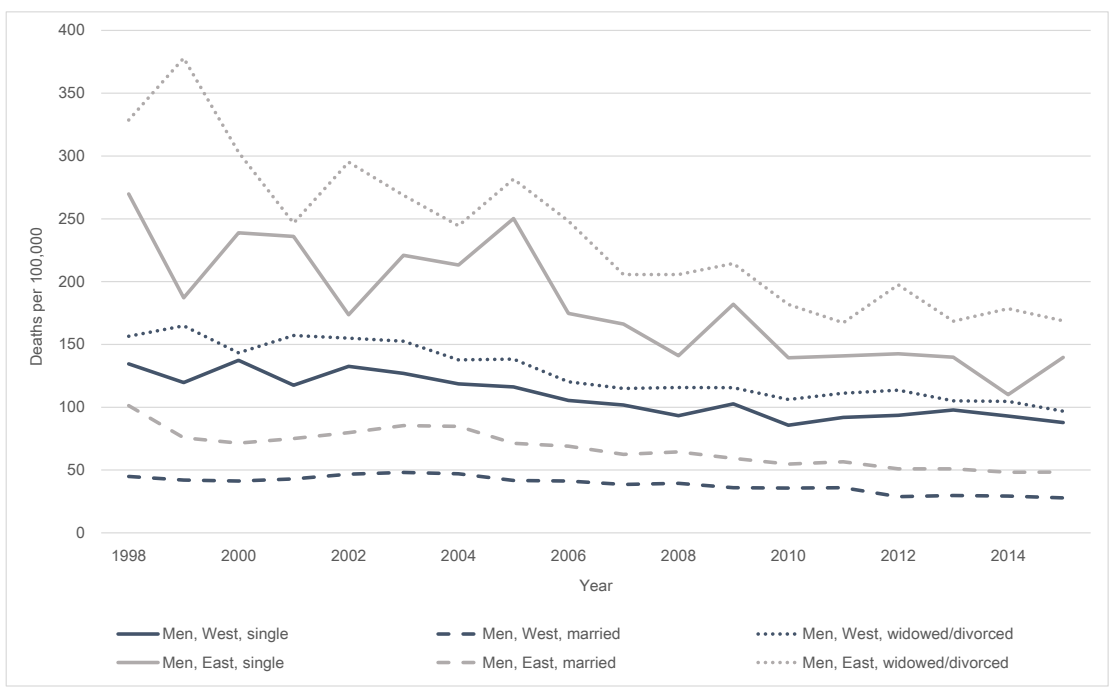

(b) Men

Fig. 6: Deaths of despair by marital status for age 50-54, Germany, 1998-2015. Mortality figures by family status are only available after 1998. Source: Federal Health Reporting and population statistics. 


\section{References}

Bulanda, J. R., Brown, J. S., and Yamashita, T. (2016). Marital Quality, Marital Dissolution, and Mortality Risk During the Later Life Course. Social Science $\& 3$ Medicine, 165:119-127.

Case, A. and Deaton, A. (2015). Rising Morbidity and Mortality in Midlife among White NonHispanic Americans in the 21st Century. Proceedings of the National Academy of Sciences, 112(49):15078-15083.

Case, A. and Deaton, A. (2017). Mortality and Morbidity in the 21st Century. Brookings Papers on Economic Activity, 2017:397-476.

Currie, J., Jin, J. Y., and Schnell, M. (2018). US Employment and Opioids: Is There a Connection? NBER Working Paper No. 24440, National Bureau of Economic Research, Cambridge, MA.

Diehl, K. (2008). Mögliche Faktoren für die rasche Reduktion der ostdeutschen Übersterblichkeit nach der Wiedervereinigung. Zeitschrift für Bevölkerungswissenschaft, 33(1):89-109.

Federal Health Reporting (2018). Statistics on the Causes of Death ("Todesursachenstatistik"); Deaths, mortality figures (from 1980); Primary source: Federal Statistical Office, Causes of Death Statistics. Data retrieved from http://www.gbe-bund.de, Retrieval date: 11/14/2018.

Federal Statistical Office (2018a). Population Statistics by Sex, Age, and Region. Data requested via https://www.destatis.de/EN/Service/Contact/Contact.html, Date: 03/14/2018.

Federal Statistical Office (2018b). Statistics of Foreigners ("Ausländerzentralregister"). Data retrieved from https://www.destatis.de, Retrieval date: 11/14/2018.

Fischer, B., Keates, A., Bühringer, G., Reimer, J., and Rehm, J. (2014). Non-Medical Use of Prescription Opioids and Prescription Opioid-related Harms: Why so Markedly Higher in North America Compared to the Rest of the World? Addiction, 109(2):177-181.

Gächter, M. and Theurl, E. (2011). Health Status Convergence at the Local Level: Empirical Evidence from Austria. International Journal for Equity in Health, 10(1):34.

Gelman, A. and Auerbach, J. (2016). Age-aggregation Bias in Mortality Trends. Proceedings of the National Academy of Sciences, 113(7):E816-E817. 
Goedicke, A. (2006a). A "Ready-Made State": The Mode of Institutional Transition in East Germany after 1989. In After the Fall of the Wall: Life Courses in the Transformation of East Germany. Stanford University Press, Stanford, CA.

Goedicke, A. (2006b). Firms and Fortune: The Consequences of Privatization and Reorganization. In After the Fall of the Wall: Life Courses in the Transformation of East Germany. Stanford University Press, Stanford, CA.

Häuser, W., Schug, S., and Furlan, A. D. (2017). The Opioid Epidemic and National Guidelines for Opioid Therapy for Chronic Noncancer Pain: A Perspective from Different Continents. Pain Reports, 2(3):e599.

Kibele, E. U. (2012). Regional Mortality Differences in Germany. Springer Science \& Business Media, Dordrecht, The Netherlands.

Kohls, M. (2008). Healthy-Migrant-Effect, Erfassungsfehler und andere Schwierigkeiten bei der Analyse der Mortalität von Migranten: Eine Bestandsaufnahme. Bundesamt für Migration und Flüchtlinge, Berlin, Germany.

Krueger, A. B. and Pischke, J.-S. (1995). A Comparative Analysis of East and West German Labor Markets: Before and After Unification. In Freeman, R. B. and Katz, L. F., editors, Differences and Changes in Wage Structures. University of Chicago Press, Chicago, IL.

Manzoli, L., Villari, P., Pirone, G. M., and Boccia, A. (2007). Marital Status and Mortality in the Elderly: A systematic Review and Meta-Analysis. Social Science $\&$ Medicine, 64(1):7794.

Mathers, C. D., Fat, D. M., Inoue, M., Rao, C., and Lopez, A. D. (2005). Counting the Dead and What They Died From: An Assessment of the Global Status of Cause of Death Data. Bulletin of the World Health Organization, 83(3):171-177.

Mayer, K. (2006). After the Fall of the Wall: Living Through the Post-Socialist Transformation in East Germany. In After the Fall of the Wall: Life Courses in the Transformation of East Germany. Stanford University Press, Stanford, CA.

Nolte, E. (2000). The Health Impact of German Unification: Still Much to Learn. Journal of Epidemiology $\mathcal{E}$ Community Health, 54(8):565-565. 
Nolte, E., Britton, A., and McKee, M. (2003). Trends in Mortality Attributable to Current Alcohol Consumption in East and West Germany. Social Science $\mathscr{E}^{3}$ Medicine, 56(7):13851395.

Nolte, E., Shkolnikov, V., and McKee, M. (2000). Changing Mortality Patterns in East and West Germany and Poland II: Short-Term Trends during Transition and in the 1990s. Journal of Epidemiology and Community Health, 54(12):899-906.

Robert Koch Institute (2011). Sterblichkeit, Todesursachen und Regionale Unterschiede. Federal Health Reporting, Robert Koch Institute, Berlin.

Ruhm, C. J. (2018). Deaths of Despair or Drug Problems? NBER Working Paper No. 24188, National Bureau of Economic Research, Cambridge, MA.

Vogt, T., van Raalte, A., Grigoriev, P., and Myrskylä, M. (2017). The German East-West Mortality Difference: Two Crossovers Driven by Smoking. Demography, 54:1051-1071.

Vogt, T. C. and Vaupel, J. W. (2015). The Importance of Regional Availability of Health Care for Old Age Survival - Findings from German Reunification. Population Health Metrics, $13(1): 26$. 


\section{A Appendix: For Online Publication}

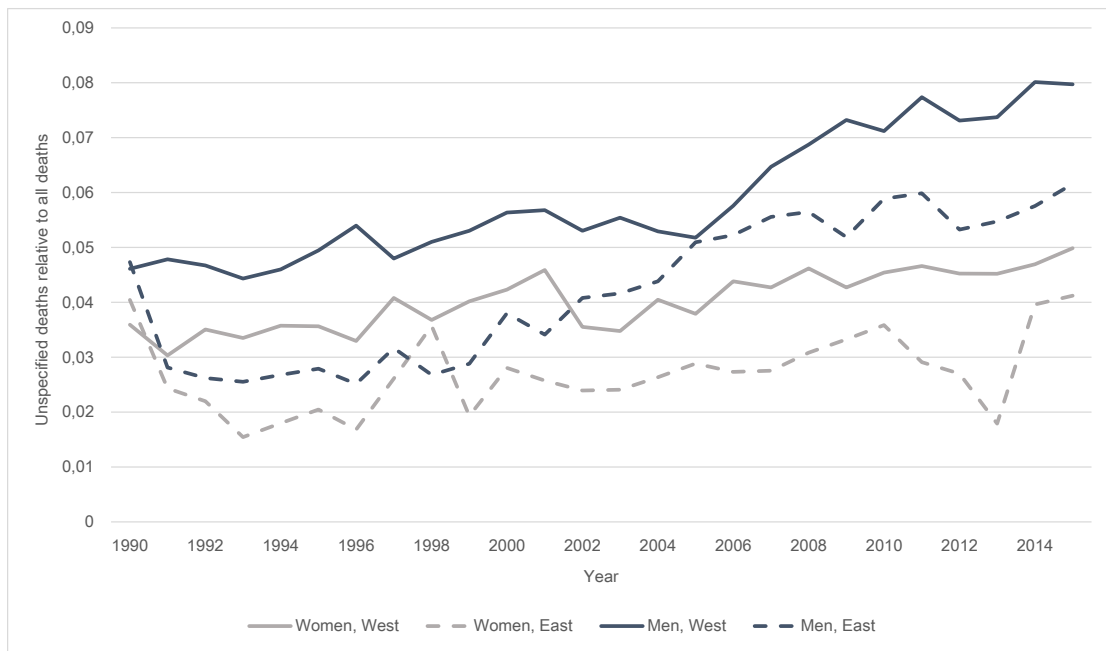

Fig. A1: Unspecified relative to all deaths for age 50-54, Germany, 1990-2015. Source: Federal Health Reporting.

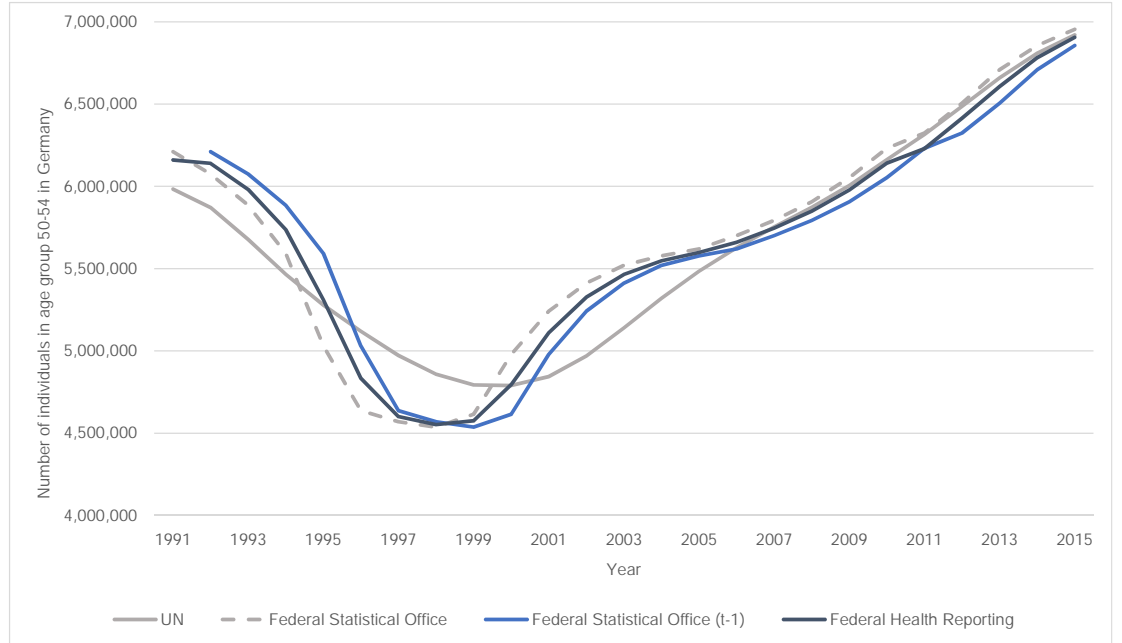

Fig. A2: Number of individuals aged 50-54 by data source, Germany, 1990-2015. Source: Federal Health Reporting, population data from the UN and the Federal Statistical Office. 


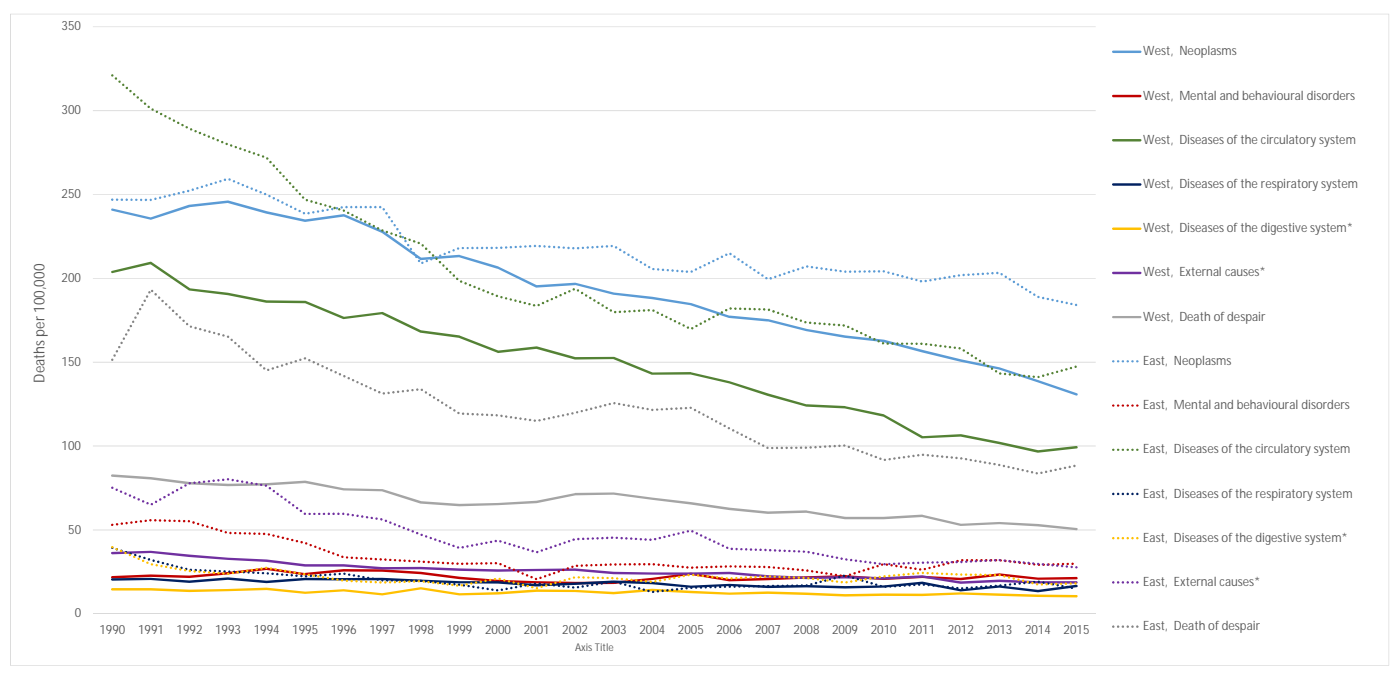

Fig. A3: Mortality for age 50-54 by cause of death, Men, Germany, 1990-2015. This figure shows mortality rates from the six most prevalent cause of deaths categories plus deaths of despair. Categories marked with a ${ }^{*}$ exclude deaths from despair within the category: Diseases of the digestive system exclude chronic liver diseases and external causes exclude poisoning and suicides. Source: Federal Health Reporting.

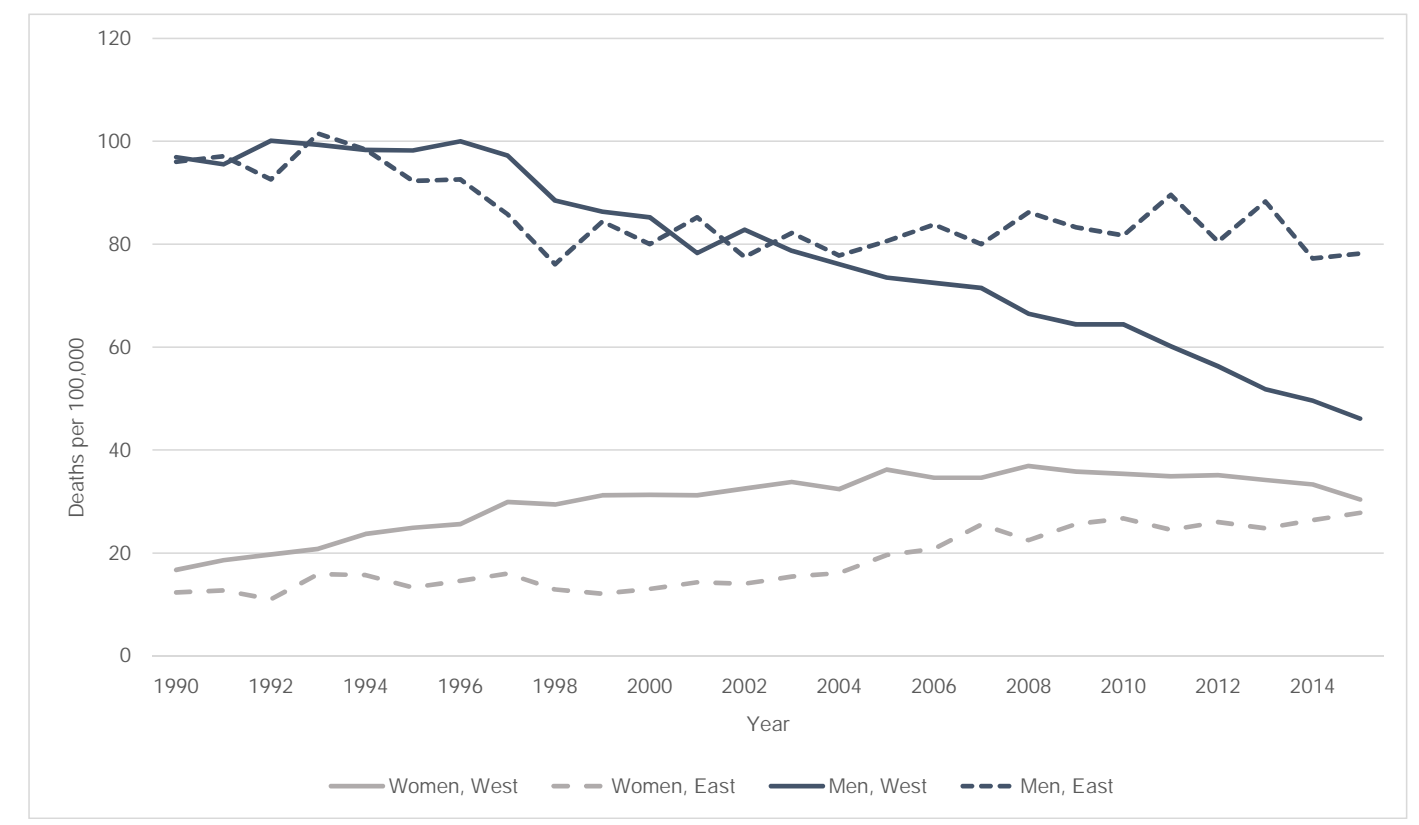

Fig. A4: Deaths by smoking for age 50-54, Germany, 1990-2015. Deaths by smoking refer to deaths from malignant neoplasms of lip, oral cavity, pharynx, larynx, trachea, bronchus and lung. Source: Federal Health Reporting. 


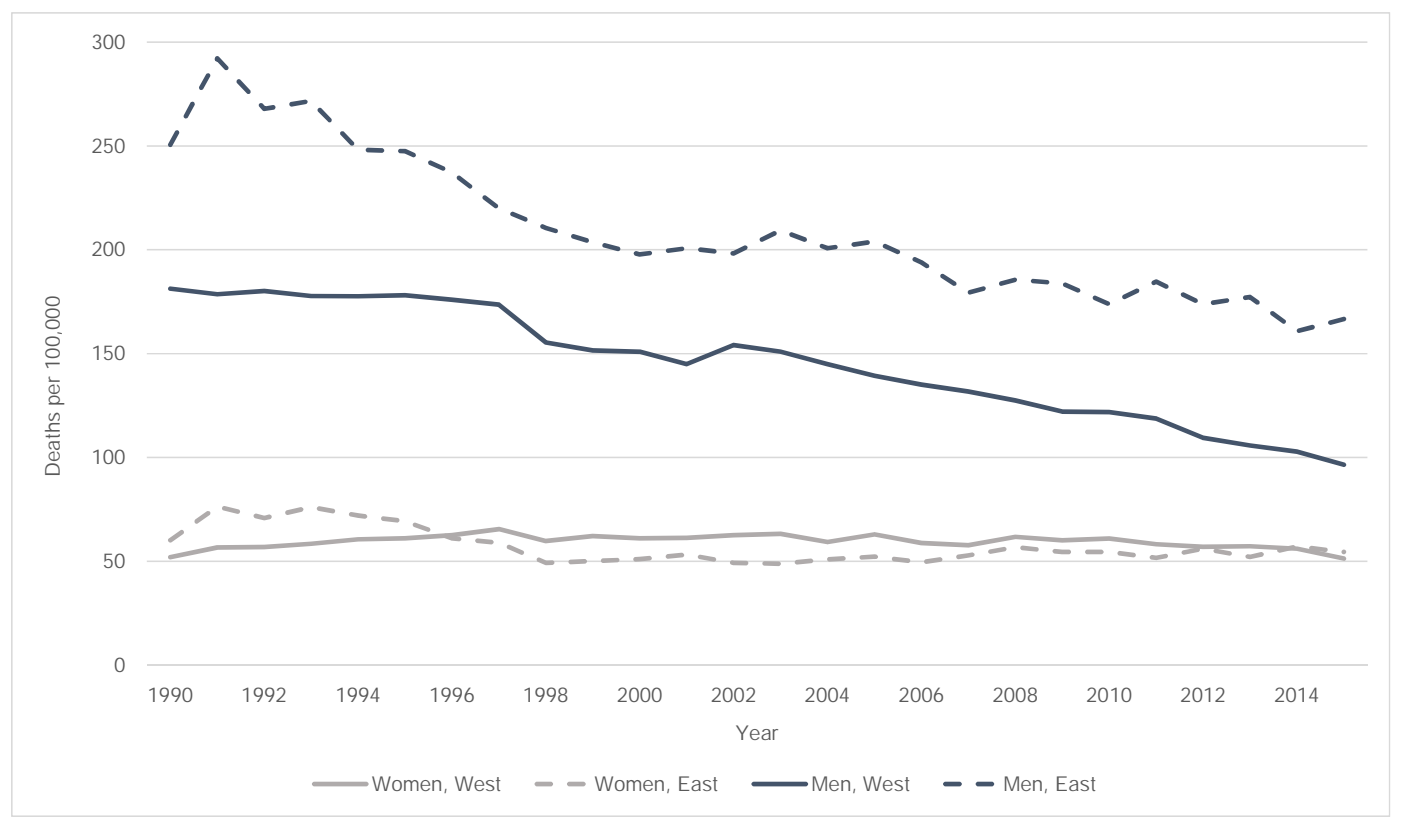

Fig. A5: Deaths of despair including deaths by smoking for age 50-54, Germany, 1990-2015. This figure shows the deaths of despair defined as in Figure 2 adding also deaths by smoking as described in Figure A4 Source: Federal Health Monitoring. 


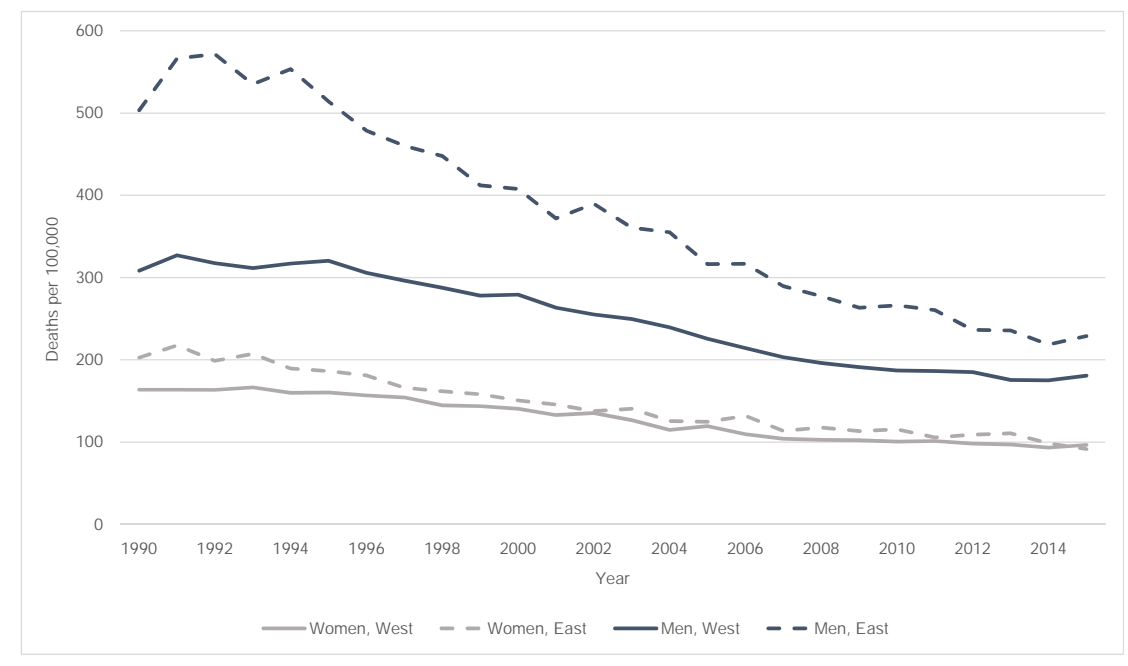

(a) All-cause

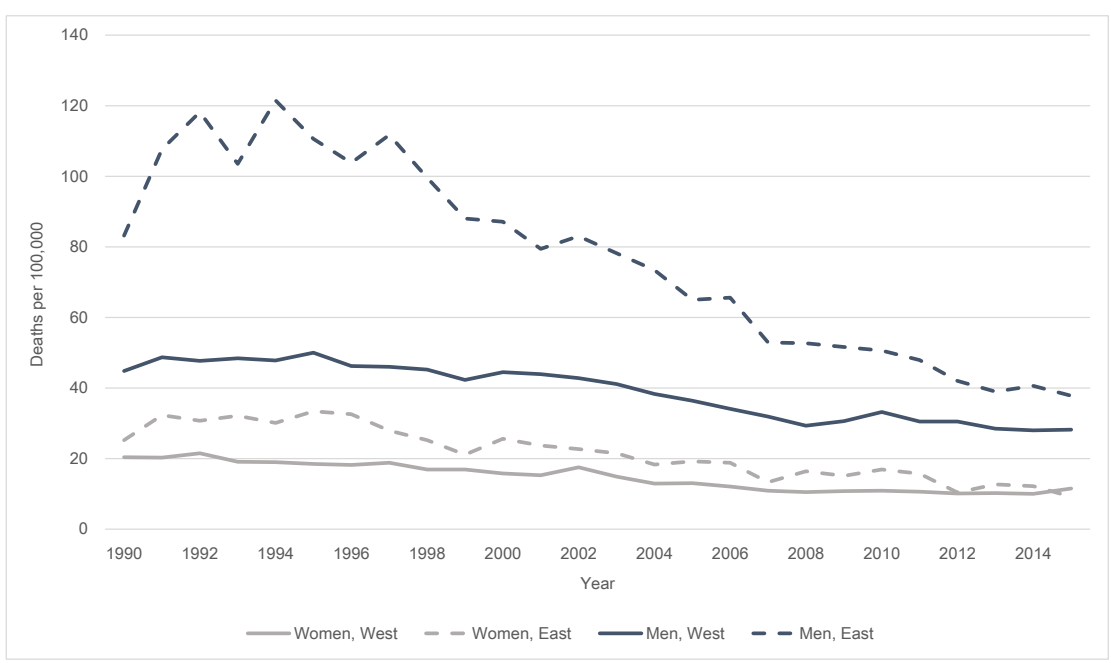

(b) Deaths of despair

Fig. A6: All-cause mortality and deaths of despair for age 40-44, Germany, 1990-2015. Source: Federal Health Reporting 


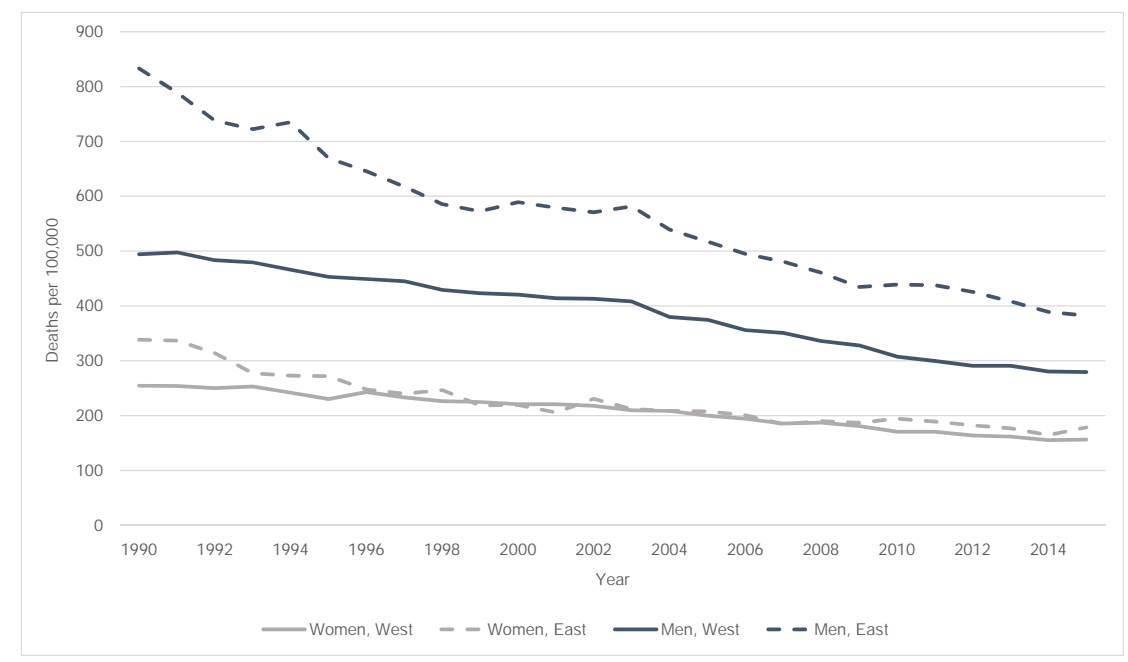

(a) All-cause

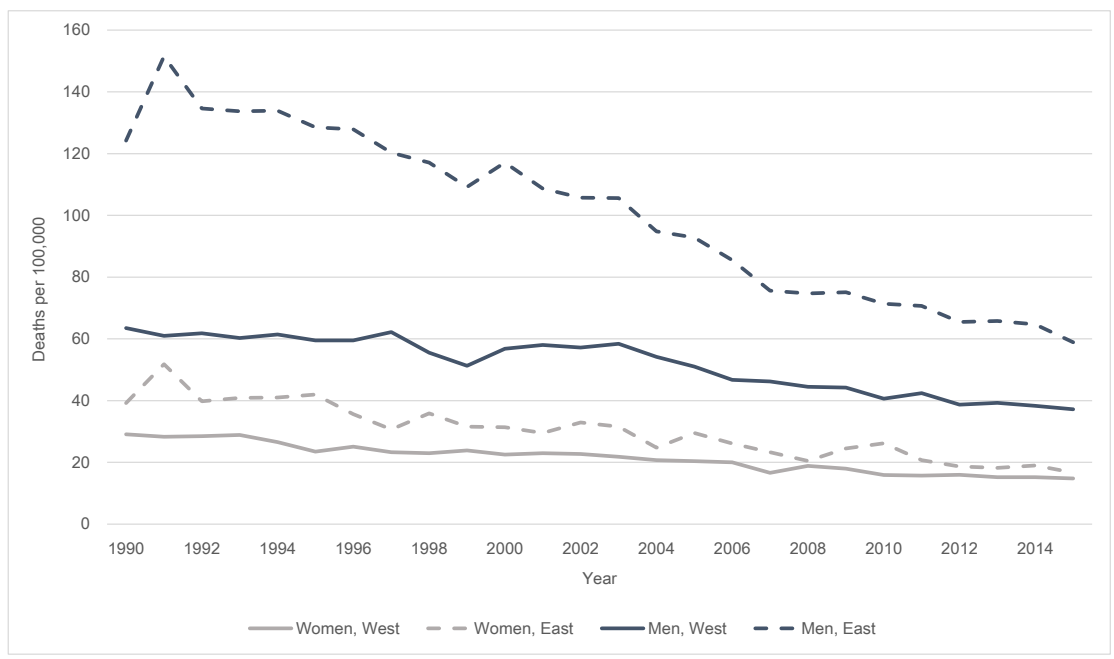

(b) Deaths of despair

Fig. A7: All-cause mortality and deaths of despair for age 45-49, Germany, 1990-2015. Source: Federal Health Reporting 


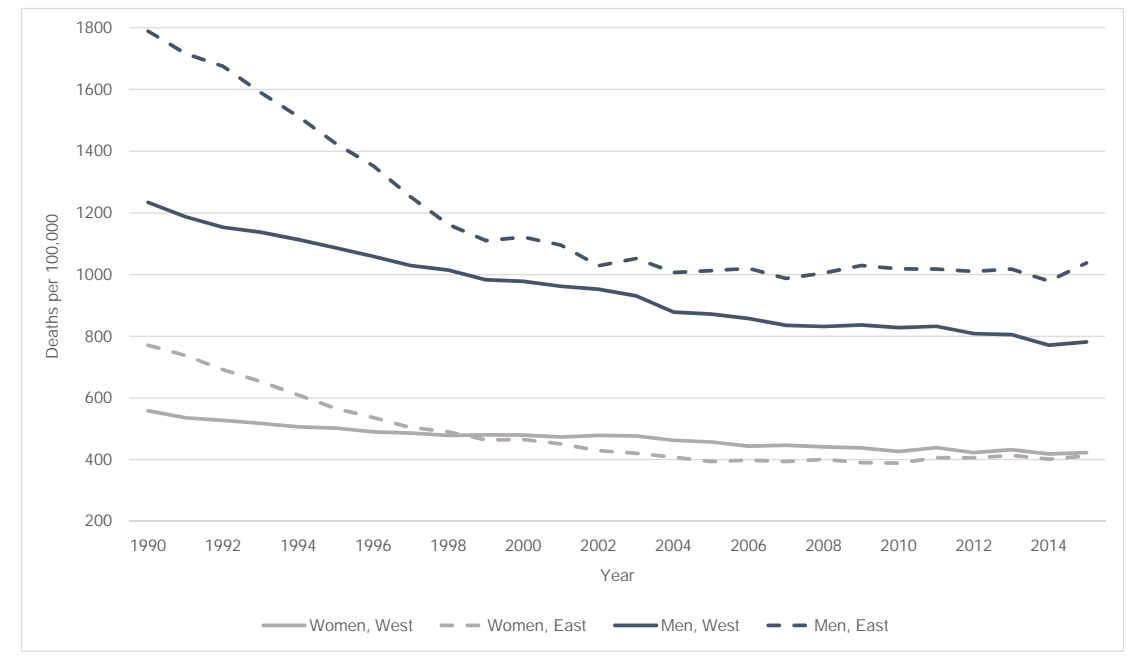

(a) All-cause

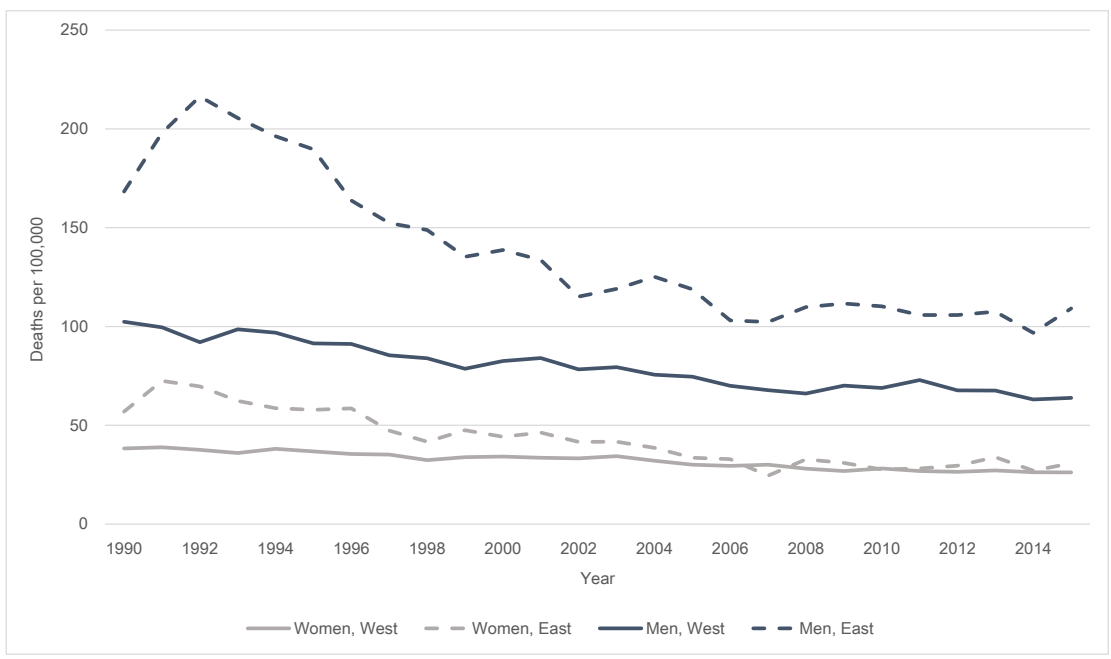

(b) Deaths of despair

Fig. A8: All-cause mortality and deaths of despair for age 55-59, Germany, 1990-2015. Source: Federal Health Reporting 